\title{
BRAIN RESPONSE TO INDUCED PERIPHERAL CANCER DEVELOPMENT IN RATS: DUAL FOS-TYROSINE HYDROXYLASE AND FOS-OXYTOCIN IMMUNOHISTOCHEMISTRY
}

\author{
Boris Mravec ${ }^{1,2}$, Lubica Lackovicova ${ }^{2}$, Zdenko PirniK² ${ }^{2}$ Jozef BiziK $^{3}$, Jana Bundzikova ${ }^{2}$, Ivan Hulin ${ }^{1}$, \\ AlEXANDER KISS ${ }^{2}$
}

\begin{abstract}
${ }^{1}$ Institute of Pathophysiology, Faculty of Medicine, Comenius University, Sasinkova 4, 81108 Bratislava, Slovak Republic; ${ }^{2}$ Laboratory of Functional Neuromorphology, Institute of Experimental Endocrinology, Slovak Academy of Sciences, Vlarska 3, 83306 Bratislava, Slovak Republic; ${ }^{3}$ Cancer Research Institute, Slovak Academy of Sciences, Vlarska 7, 83391 Bratislava, Slovakia

e-mail: boris.mravec@fmed.uniba.sk
\end{abstract}

\begin{abstract}
Objective. During last few decades a considerable number of data has emerged supporting the hypothesis that central nervous system might monitor and modulate tumor growth. This assumption is based on two facts: 1 . immune system plays a crucial role in the development and progression of cancer; 2 . immune and nervous systems communicate tightly and bidirectionally. The aim of present study was to elucidate whether tumor growth may induce detectable changes in brain structures that are involved in the response to immune challenges.

Methods. Using Fos immunohistochemistry, we investigated whether the advanced stage of cancer, induced by a single intraperitoneal injection of BP6-TU2 fibrosarcoma cells to male Wistar rats, could activate Fos expression in the nucleus of the solitary tract (NTS), amygdala and parabrachial nuclei (PBN) and also activate some of neuronal phenotypes including tyrosine hydroxylase (TH) neurons in the brainstem noradrenergic cell groups and hypothalamic oxytocinergic neurons.

Results. Twenty eight days after the initiation of tumor process we found increased Fos expression in NTS/A2, A1 noradrenergic cells, PBN as well as in the hypothalamic paraventricular, supraoptic and accessory oxytocinergic neurons. These structures are involved in the transmission of signals related to immune challenges within the brain and consequent elaboration of neuro-endocrine responses.

Conclusions. The data obtained are supporting the view that the information on peripheral tumor development might be transmitted to the brain. However, further studies are necessary to be performed to reveal whether our findings can be attributed to specific effect of cancer or whether observed changes in the activity of brainstem and hypothalamic neurons reflex processes that only accompany the cancer progression.
\end{abstract}

Keywords: Brainstem noradrenergic cells - Cancer - Hypothalamic oxytocinergic cells - Immune system - Nervous system - Cancer neurobiology - Rat

Development of cancer is a complex process modulated by a number of different factors from which many remain still unknown (HANAHAN and WeINBERG 2000;
MAREel and Leroy 2003). Cancer progression is modulated by tumor-related circumstances and also by characteristics of the host. Tumor-related conditions include

Corresponding author: Boris Mravec, MD., PhD., Institute of Pathophysiology, Faculty of Medicine, Comenius University, Sasinkova 4, 811 08 Bratislava, Slovak Republic; Phone: +421 2 59357389; Fax: +421 2 59357601, e-mail: boris.mravec@ fmed.uniba.sk 
the tumor aggressiveness that is determined by the tissue type and the degree of its dedifferentiation, functionality of apoptosis, DNA repair mechanisms, loss of contact inhibition, and ability to induce a vascular supply and metastasis. Resistance of the host depends on the immune competence (DunN et al. 2004). It is becoming more evident that also neuro-immune mechanisms which are subordinated to the brain and behavior, play a role in the defense against cancer development and its progression (BERCZI et al, 1998; ENTSCHLADen et al. 2002; LANG et al. 2006; SePhton And Spiegel, 2003). It has been hypothesized that the brain might monitor and modulate the process of tumorigenesis (Esteban et al. 2006; GidRon et al. 2005; Mravec et al. 2006; MRAVEC and Hulin, 2006). Based on this hypothesis as well as on experimental and clinical observations, a novel view of tumor etiopathogenesis was emerged, which has been entitled neurobiology of cancer as explained by MRAVEC et al. (2008). However, it is necessary to take in consideration that the interactions between the cancer and brain are considerably complicated and according to the nature of the neoplasm many variations may occur (CONTI 2000).

There exist a number of studies attempting to circumscribe possible effects of psycho-neuro-immunological interactions on the genesis and progression of cancer. These publications underlined mainly the role of descending pathways represented by sympathoadrenal and hypothalamo-pituitary adrenocortical systems in the modulation of tumorigenesis (KIECOLT-Glaser and Glaser, 1999; Reiche et al. 2005; Spiegel 1999). However, the number of studies dealing with the transmission and processing of cancer-related signals by the brain, are still limited (KerGOZIEN et al. 1999; KonsMAN and BLOMQvist, 2005).

The aim of present study was to elucidate whether the advanced stage of tumor growth, induced by a single intraperitoneal injection of BP6-TU2 fibrosarcoma cells, may evoke detectable changes in the brain structures that are involved in the response to immune challenges, including brainstem viscerosensory relay nuclei (noradrenergic cell groups A1, A2, A5, A6, parabrachial nucleus and brainstem circumventricular organ area postrema), hypothalamic neuroendocrine centers (paraventricular, supraoptic, accessory nuclei) and such center for emotional events as amygdala, by employing Fos immunohistochemistry. In selected areas also TH and OXY phenotypic identifications of activated neurons were performed by using Fos/TH and Fos/OXY dual immunohistochemistry.

\section{Materials and Methods}

Animals. All experiments were carried out in male Wistar rats (obtained from AnLab, Prague, Czech Republic). During the experiment, the animals were kept in an animal facility under controlled conditions (12 $\mathrm{h}$ light/12 h dark cycle, lights at 06:00 h; temperature, $22 \pm 1{ }^{\circ} \mathrm{C}$ ) and with free access to tap water and standard pelleted rat chow. The experiments were performed between 08:00-14:00 $\mathrm{h}$ and the animals were protected from all external noises or other possible stressful stimuli. All experimental procedures were approved by the Animal Care Committee of the IEE SAS Bratislava, Slovak Republic. The investigation conforms also to the Guide for the Care and Use of Laboratory Animals published by the U.S. National Institutes of Health.

Induction of tumors. Rat fibrosarcoma cell line (BP6TU2) routinely cultured in RPMI 1640 medium containing $10 \%$ FCS plus antibiotics was used. Animals $(\mathrm{n}=25)$ weighing $150 \pm 20 \mathrm{~g}$ were injected intraperitoneally by a single injection of $0.5 \times 10^{6}$ amount of the fibrosarcoma cells dispersed in $2.0 \mathrm{ml}$ of serum-free RPMI 1640 medium. Control rats $(n=12)$ were exposed to the same volume of the serum-free medium. The tumors developed in $68 \%$ of animals that received intraperitoneal injection of BP6 cells, while in $32 \%$ of injected rats no tumor mass was macroscopically detectable in the abdominal cavity. During the experiments, $11 \%$ of animals failed to survive the process of tumor growth. At the end of experiment, i.e. 28 days after cancer cells implantation, the rats were sacrificed by intracardial perfusion with fixative. The process of tumor growth was considered to be effective when 28 days after the cancer cells implantation a tumor mass was developed in the abdominal cavity. No metastases were detected in tumor-bearing animals which showed a $6.5 \%$ loss of body weight when compared to control animals at the day of perfusion.

Imunohistochemistry. The rats were anesthetized by pentobarbital $(50 \mathrm{mg} / \mathrm{kg}$, Spofa, Prague, Czech Republic) and perfused transcardially with $250 \mathrm{ml}$ fixative solution consisting of $0.1 \mathrm{M}$ phosphate buffer (PB, $\mathrm{pH}$ 7.4) containing $4 \%$ paraformaldehyde. Then the brains were removed, postfixed in the same fixative overnight at $4{ }^{\circ} \mathrm{C}$ and infiltrated with $15 \%$ sucrose in $0.025 \mathrm{M} \mathrm{PB}$ for $48 \mathrm{~h}$ at $4{ }^{\circ} \mathrm{C}$. Quickly frozen brains in cold isopentane $\left(-30 /-40{ }^{\circ} \mathrm{C}\right)$ were sectioned into 30 ěm thick coronal sections over the hypothalamus, caudal midbrain, and brainstem areas in a Reichert cryocut device adjusted to $-16^{\circ} \mathrm{C}$. The sections were collected as free floating in a cold $\left(+4^{\circ} \mathrm{C}\right) \mathrm{PB}$. 
The sections were washed in PB and preincubated with $3 \% \mathrm{H}_{2} \mathrm{O}_{2}$ for $30 \mathrm{~min}$. Then they were incubated with a polyclonal Fos protein antiserum (No 94012, 1:2000), in $0.1 \mathrm{M} \mathrm{PB}$ containing $4 \%$ normal goat serum (Gibco, Grand Island, NY, USA), $0.5 \%$ Triton X-100 (Koch-Light Lab. Ltd., Colnbrook, Berks, England), and $0.1 \%$ sodium azide (Sigma Chemical Ltd., St. Louis, MO, USA) for $48 \mathrm{~h}$ at $4{ }^{\circ} \mathrm{C}$. After several washes in $\mathrm{PB}$, the sections were incubated with biotinylated goat-antirabbit IgG (1:500, VectorStain Elite ABC, Vector Lab., Burlingame, CA, USA) for $90 \mathrm{~min}$. Next PB rinses were followed by incubation with the avidin-biotin peroxidase complex (1:250) for $90 \mathrm{~min}$. PB washes were followed by rinsing in $0.05 \mathrm{M}$ sodium acetate buffer (SAB, pH 6.0). The Fos reaction was visualized with $0.03 \%$ 3,32-diaminobenzidine tetrahydrochloride (DAB, Sigma) in SAB containing $0.003 \% \mathrm{H}_{2} \mathrm{O}_{2}$ and $2.5 \%$ nickel ammonium sulfate (Sigma). After several washes in PB, the Fos-positive sections were incubated with TH (1:2000) or OXY (1:2000) antibodies using the same procedure as described above. The TH and OXY immunoreactivities were developed by $0.0125 \%$ DAB chromogen dissolved in $0.05 \mathrm{M}$ Tris $(\mathrm{pH}$ 7.4) containing and $0.003 \% \mathrm{H}_{2} \mathrm{O}_{2}$ until an appropriate tawny color was reached. Finally, the sections were rinsed in $0.05 \mathrm{M}$ Tris buffer followed by $0.05 \mathrm{M}$ SAB buffer, mounted into $0.1 \%$ of gelatine dissolved in $0.0125 \mathrm{M} \mathrm{SAB}$, airdried, coverslipped with Permount (Sigma), and examined under Leica DMLS light microscope. Immunostaining of negative control, which did not show any antiserum immunolabeling, included substitution of the primary antisera with normal rabbit serum, and sequential elimination of the primary or secondary antibody from the staining series.

Evaluation of immunostainings. The cell counting was performed on $30 \mu \mathrm{m}$ thick serial coronal sections employing a computerized system that included Leica DMLS light microscope equipped with a Canon digital camera (PowerShot S40). The quantitative assessment was performed from the captured images on a computer screen obtained from 4-8 brain sections/ rat from each brain area selected, i.e. Fos only in the parabrachial nucleus, amygdala, and NTS; Fos/TH colocalizations in the A1, A2, A5, A6, A7 and the area postrema brainstem cell groups, and Fos/OXY colocalizations in the paraventricular, supraoptic, and accessory nuclei of the hypothalamus. The percentage of activated TH or OXY neurons was calculated from the ratio of the amount of TH or OXY perikarya displaying Fos signal deducting from the total $\mathrm{TH}$ or OXY immunolabeled perikarya x 100.
Antibodies. Fos antiserum (No 94012) was raised against the N-terminal peptide similar to 2-17 of the rat Fos protein according to the protocol described elsewhere (MiKKELSEN et al. 1998) and was provided by Dr. J.D. Mikkelsen (NeuroSearch A/S Ballerup, Denmark). The polyclonal antisera to oxytocin and tyrosine hydroxylase were purchased from Chemicon International, Inc. (Temicula, CA, USA), cat \# AB 911 and cat \# AB 151, respectively.

Statistical evaluation. All data represent the mean \pm SEM. For statistical comparisons t-test was used, $\mathrm{p}<0.05$ being considered as statistically significant.

\section{Results}

Effect of tumors on single Fos expression. In the amygdala, hypothalamus (Fig. 1A, C), PBN (Fig. 2A), and brainstem of controls, i.e. animals injected intraperitoneally with serum-free medium, single Fos labeled perikarya occurred only sporadically. In contrast to controls, a clear accumulation of Fos immunoreactivity was found in PVN (Fig. 1B), SON (Fig. 1D), several accessory nuclei (Fig.3A), PBN (Fig. 2B), NTS/A2 (Fig. 2C) and A1 (Fig. 2D) noradrenergic cell groups in the tumor-bearing rats. In the amygdalar subdivisions and A7 noradrenergic cell group no visible response to tumor growth was observed (not shown), i.e. the amount of the Fos labeled neuronal perikarya in these areas did not exceed the amount of Fos labelings observed in the control animals.

Effect of tumors on the hypothalamic oxytocinergic neurons. Hypothalamic sections of control rats injected intraperitoneally with serum-free medium, showed only a sparse Fos expression over the whole hypothalamus, however none of OXY perikarya exhibited Fos immunoreactivity.

Oxytocin immunoreactive neurons expressing Fos (Fos/OXY) were analyzed in hypothalamic paraventricular nucleus, SON, and magnocellular accessory (Acc) cell groups. The greatest incidence of Fos/OXY colocalizations was found in PVN (Fig. 4A) and adjacent periventricular nucleus (Fig. 3B) of tumor-bearing rats, while in SON (Fig. 4B) and Acc (Fig. 3A,C) the Fos/OXY colocalizations were observed less frequently. Among the Acc magnocellular nuclei mainly the circular (Fig. 3A) and perifornical ones (Fig. 3C) revealed Fos/OXY double stainings.

Effect of tumors on the brainstem noradrenergic neurons. Incidence of $\mathrm{TH}$-immunoreactive neurons expressing Fos immunoreactivity (Fos/TH) was count- 


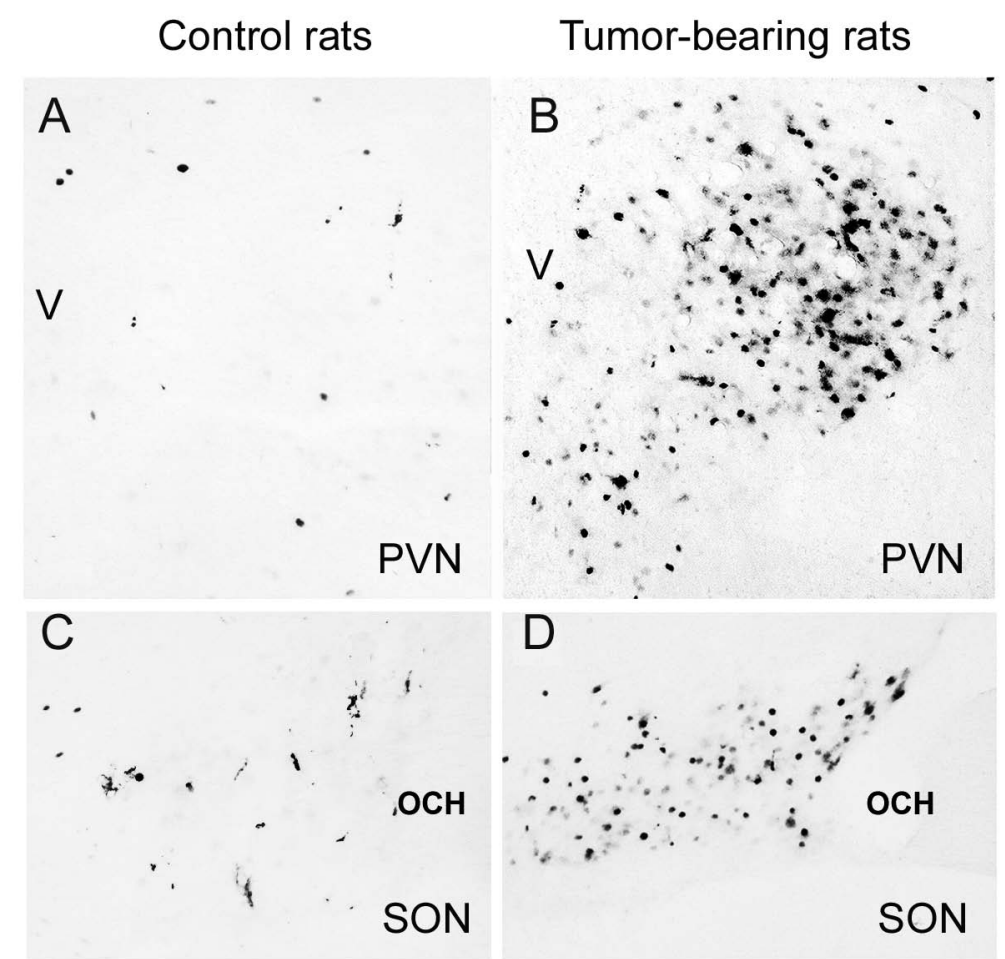

Fig. 1 Effect of 28 days lasting tumor growth on the Fos expression in the PVN and SON neurons. In the PVN (A) and SON (C) of controls only scattered Fos is observable while in the PVN (B) and SON (D) of tumor-bearing rats many cells display Fos immunoreactity. Abbreviations: V - 3rd ventricle; OCH - optic chiasm.

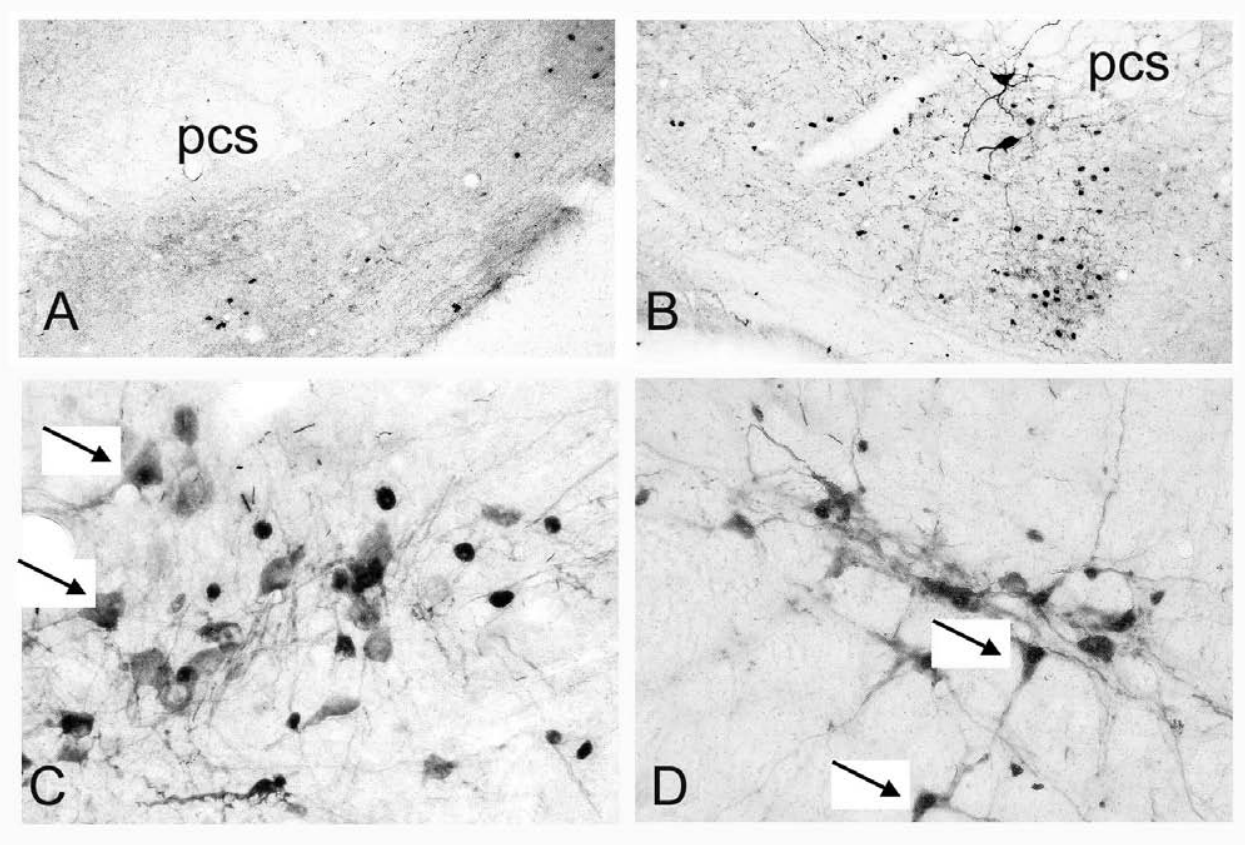

Fig. 2 Effect of 28 days lasting tumor growth on the Fos expression in the parabrachial nucleus and Fos/TH colocalizations in the NTS/A2 and A1 cell groups. Parabrachial nucleus of tumor-bearing rats (B) contains markedly more Fos profiles then controls (A). In the NTS/A2 (C) and A1 (D) areas of tumor-bearing rats many free Fos and a few colocalized Fos/TH (arrows) are visible. Abbreviations: pcs - superior cerebellar peduncle. 

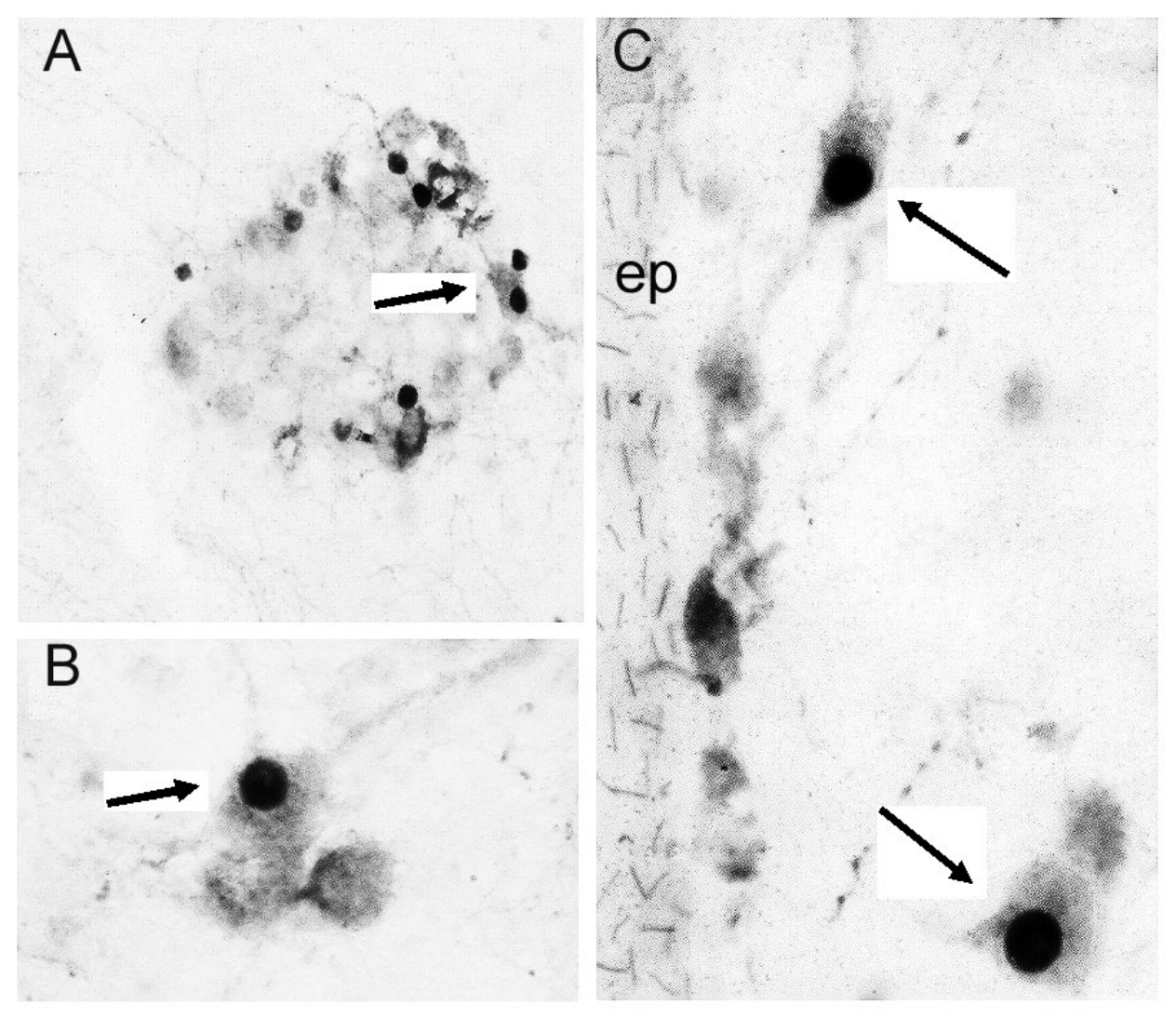

Fig. 3 Effect of 28 days lasting tumor growth on the Fos/OXY colocalizations (arrows) in the hypothalamic circular (A), periventricular (B), and perifornical (C) nuclei of tumor-bearing rats. Abbreviations: ep - ependymal lining of the 3rd ventricle.

ed in the noradrenergic cell groups localized in pons (A5, A6, A7) and medulla oblongata (A1, NTS/A2). Brainstem sections from control rats injected i.p. with serum-free medium, showed only a sparse Fos expression in many brain areas including the medulla oblongata. However, none of the investigated noradrenergic cell groups exhibited Fos/TH colocalizations in controls (not shown).

In tumor-bearing animals, the highest degree of colocalizations of TH/Fos neurons was observed in NTS/ A2 noradrenergic cell group (Fig. 2C) $(8.0 \%, p<0.05)$. Substantially lower incidence of TH/Fos double labeled perikarya was seen in the cells of A1 noradrenergic cell group (Fig. 2D) (1.4\%) of the lateral reticular nucleus. Other noradrenergic cell groups, including A5 and A7, exhibited less than $1 \%$ of Fos/TH colocalizations in the tumor-bearing rats (Fig. 5).

The number of Fos activated cells in locus coeruleus (LC, A6), with respect to the high density of TH immunoreactive cells, was not counted as a ratio of Fos/
TH colocalizations but only as a total number of superimposed Fos profiles over the LC territory delineated by TH cell perikarya. In the tumor-bearing animals, the Fos profiles occurred only sporadically in LC, i.e. 5-6 Fos profiles/1 LC area. Likewise LC, area postrema also revealed only a limited number of Fos activated cells, i.e. 2-3 Fos profiles/1 AP area/section (not shown).

\section{Discussion}

The aim of this study was to reveal more information regarding possible interactions between the tumor tissues and brain. Our attempt was to assess whether the peripheral tumor growth lasting 28 days and induced by direct intraperitoneal implantation of fibrosarcoma cells may affect some brain areas that are sensitive to immune challenges. As indicator of cell activation, Fos protein immunohistochemistry was employed (HoFfMAN et al. 1993). Although this protoontogen is usually 


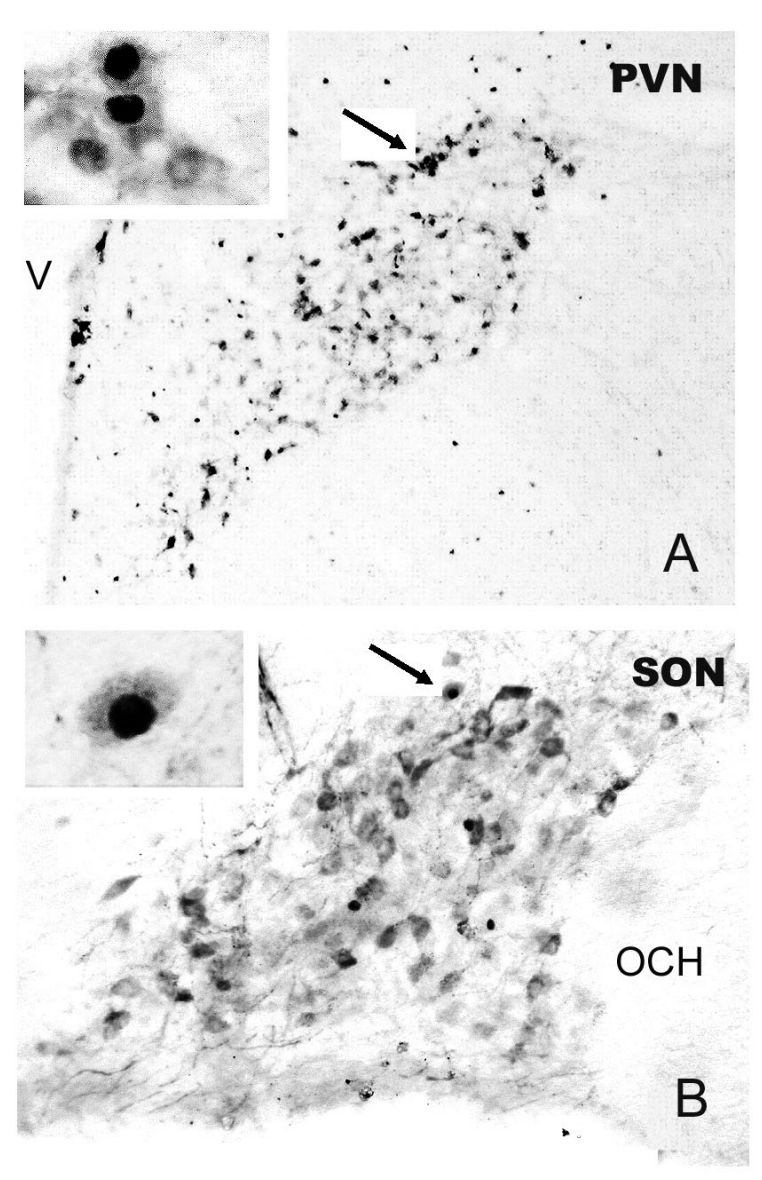

Fig. 4 Effect of 28 days lasting tumor growth on the Fos/OXY colocalizations in the PVN and SON neurons. In both the PVN (A) and SON (B) of tumor-bearing rats several OXY cell display Fos immunoreactivity (arrows). Inserted pictures show a detailed view on the Fos/OXY double labeled perikarya. Abbreviations: V - 3rd ventricle; OCH - optic chiasm.

used for the identification of acute cell responses, many studies, including ours (PIRNIK et al. 2003) clearly show that Fos protein presence can also be used as a marker of chronic as well as repeated stimulations of nerve cells (HEBERT et al. 2005).

In the present study we demonstrate that 28 day lasting peripheral experimental tumor process shows increased Fos expression of neurons in several brain areas including TH immunoreactive cells in the NTS/ A2, A1 noradrenergic cells and PBN as well as in OXY synthesizing cells in the hypothalamic paraventricular, supraoptic, and accessory nuclei. Since these structures are involved in the transmission of signals related to immune challenges within the brain and in the elabo-

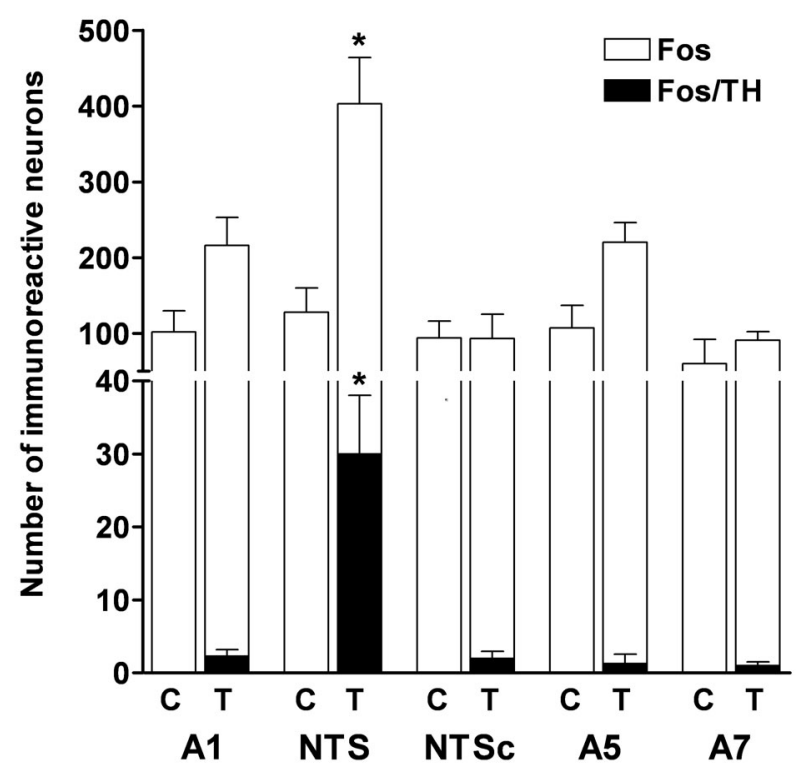

Fig. 5 Effect of 28 days lasting tumor growth on the Fos expression in tyrosine hydroxylase immunoreactive cells in brainstem of controls $(C ; n=3)$, and tumor-bearing $(T ; n=4)$ rats. Each value is the mean \pm SEM. Statistical significance compared to matched control group: * $\mathbf{p}<\mathbf{0 . 0 5}$. Abbreviations: NTS - nucleus of the solitary tract; NTSc - nucleus of the solitary tract; commissural part; A1, A5, A7 - brainstem noradrenergic cell groups.

ration of appropriate neuro-endocrine responses, we imply that the brain may receive information about cancer development at the periphery and it can probably also modulate its progression.

Involvement of the nervous system in the monitoring and modulation of development and progression of cancer has been indicated by several clinical and experimental data (ERIN et al. 2004; ERIN et al. 2006; Hodgson et al. 1998; Hodgson et al. 1999; Leo and Bonneau, 2000). General approach is focused on the role of sympathoadrenal system and hypothalamo-pituitary adrenocortical axis in the modulation of tumor progression by the brain (ANTONI et al. 2006; BENELIYAHU et al. 2007). Although some published data deals also with the hypothesis that the brain may monitor the process of tumor growth (GIDRON et al. 2005; Mravec et al. 2006; MraveC and Hulin, 2006) studies concerning the transmission of tumor-related signals to the brain are rather sporadic.

Immunohistochemical mapping of Fos expression in tumor-bearing rats (KERGOZIEN et al. 1999) demonstrate that peripheral tumor growth may stimulate neu- 
rons in central nervous system. Thus-Konsman and BLOMQUIST (2005) have revealed changes in the activity of forebrain structures indicating that these changes are related to the tumor-associated anorexia-cachexia. Besides animal studies, changes in the brain activities have been also described in patients suffering from cancer (TASHIRO et al. 2000). However, the interpretation of the findings obtained in patients remains still difficult.

Single Fos expression was markedly elevated in NTS and PBN, less distinctly in the area postrema, but it was completely missed in the amygdala of tumor-bearing rats. Our attempt was to reveal Fos response in TH and OXY neuronal phenotypes involved in the response of tumor growth in the brainstem noradrenergic cell groups and in the hypothalamic paraventricular, supraoptic and accessory nuclei. Actually, these structures are known to participate significantly in the transmission and processing of signals related to immune challenges (GAYKEMA et al. 2007; Hollis et al. 2004; MASEK et al. 2003; YANG et al. 2000). Moreover, oxytocin has been shown to have immunomodulatory properties (YANG ET AL., 1997) and his relevance to tumorigenesis come out from his role in suppressing the proliferation of tumor cells (CASsONI et al. 2004).

$>$ From our experiments several assumptions may be drawn as related to the monitoring and modulation of tumor progression by the brain. Since the tumor occurrence was restricted to the abdominal cavity, we assume that the increased Fos incidence in NTS/A2 and A1 TH labeled neurons in tumor-bearing animals may indicate the transfer of peripheral signals to NTS by the vagus nerve. Actually, the vagus nerve quite densely innervates the peritoneal cavity and NTS neurons represent the relay station for immune signals carried by ascendent vagal pathway (GoEHLER et al. 2000). We suppose that increased Fos immunoreactivity in NTS/A2 and the activation of TH immunolabeled neurons in NTS/A2 may indicate that the vagus nerve could be involved in the transmission of information related to peripherally localized tumor progression and that catecholaminergic cells are also a part of this process. It is well documented that visceral fibers of the vagus nerve contain a variety of sensory receptors (PaINTAL 1973) and that the vagal sensory neurons themselves express mRNA for IL-1 receptors (ЕK ЕT AL., 1998). Therefore, we assume that cytokines produced by immune cells, as a response to tumor proliferation, might activate the sensory afferents of the vagus nerve, which might subsequently transmit signals from the abdominal cavity to the nucleus of the solitary tract.

However, our data do not allow to determine, whether the increased Fos immunoreactivity in NTS neurons may reflect solely the immune system reaction to tumor growth, or whether the activation of these neurons represents a reaction to activated abdominal mechanoreceptors as a consequence of the tumor mass growth in abdominal cavity in which even the changes in food passage or other concurrent processes accompanying tumor proliferation may interfere. Moreover, it is necessary to take into consideration that besides of vagal afferent pathway activation, the role of primary afferent fibers of neurons localized in dorsal root ganglia of abdominal spinal cord cannot be excluded regarding the activation of NTS/A2 noradrenergic neurons (NANCE and SANDERS, 2007). In addition, the tumorrelated signals might reach the NTS cells also by a humoral way (QUAN and BANKS, 2007). However, this case seems to be less likely, since we found only very limited Fos immunoreactivity in the area postrema cells of tumor-bearing rats when compared to matched controls. Eventually, we can speculate that the faint increase of Fos expression in area postrema neurons might reflect an adaptation of neurons to long lasting activation to cancer-related humoral changes. A1 noradrenergic neurons also participate in the transmission of immune signals to higher brain structures, including parabrachial nucleus, hypothalamus, and amygdala (GAYKEMA et al. 2007). There remains a question whether low levels of Fos expression in A1 cells might indicate the involvement of these neurons in the transmission of cancer-related signals from the lower brainstem to the forebrain structures. Parabrachial nucleus is an important structure involved in the transmission of immune signals within the brain (BULLER et al. 2004) Increased Fos expression in these neurons in tumor-bearing rats might indicate involvement of PBN in the transmission of tumor-related signals to forebrain structures.

We also found increased Fos expression in PVN of tumor-bearing rats. It is well known that particularly the PVN neurons contribute significantly to central response elicited by systemic immune challenge (BULLER et al. 2003; YANG et al. 1997). Moreover, PVN represents an important nodal point for the coordination of autonomic, endocrine, and immune systems activities (WRONA 2006). Therefore we suggest that the activation of the PVN neurons may be one of the acceptable facts indicating that the brain might elaborate a neuroendocrine-immune response to tumor growth. 
In conclusion, our findings support the notion that specific brain areas may be informed about the tumor progression at the periphery, i.e. far from the brain, which could provide a basis for a neurobiological view on cancer (Mravec et al. 2008). However, further studies including selective blockade of different types of peripheral receptors, using a wider scale of activation markers and different time intervals, are necessary to be performed to reveal whether our findings can be attributed to specific effect of cancer or whether observed changes in the activity of brainstem and hypothalamic neurons reflex processes that only accompany the cancer progression (increased intraperitoneal pressure, anorexia-cachexia, ect.).

\section{Acknowledgments}

This work was supported by Slovak Research and Development Agency under the contract No. APVV-0045-06 and by grants of VEGA (1/4312/07, 2/6017/26), and CE SAS CENDO.

\section{References}

Antoni MH, Lutgendorf SK, Cole SW, Dhabhar FS, Sephton SE, McDonald PG, Stefanek M, Sood AK: The influence of biobehavioural factors on tumour biology: pathways and mechanisms. Nat Rev Cancer 6, 240-248, 2006 doi:10.1038 nrc1820 PMid:16498446

Ben-Eliyahu S, Page GG, Schleifer SJ: Stress, NK cells, and cancer: Still a promissory note. Brain Behav Immun 21, 881-887, 2007 doi:10.1016/j.bbi.2007.06.008

Berczi I, Chow DA, Baral E, Nagy E: Neuroimmunoregulation and cancer (review). Int J Oncol 13, 1049-1060, 1998

Buller KM, Allen T, Wilson LD, Munro F, Day TA: A critical role for the parabrachial nucleus in generating central nervous system responses elicited by a systemic immune challenge. J Neuroimmunol 152, 20-32, 2004 doi:10.1016/j.jneuroim.2004.03.013 PMid:15223234

Buller KM, Dayas CV, Day TA: Descending pathways from the paraventricular nucleus contribute to the recruitment of brainstem nuclei following a systemic immune challenge. Neuroscience 118, 189-203, 2003 doi:10.1016/S0306-4522(02)00808-4 PMid:12676149

Cassoni P, Sapino A, Marrocco T, Chini B, Bussolati G: Oxytocin and oxytocin receptors in cancer cells and proliferation. J Neuroendocrinol 16, 362-364, 2004 doi:10.1111/j.0953-8194.2004.01165.x PMid:15089975

Conti A: Oncology in neuroimmunomodulation. What progress has been made? Ann N Y Acad Sci 917, 68-83, 2000

Dunn GP, Old LJ, Schreiber RD: The immunobiology of cancer immunosurveillance and immunoediting. Immunity 21, 137-148, 2004 doi:10.1016/j.immuni.2004.07.017 PMid:15308095

Ek M, Kurosawa M, Lundeberg T, Ericsson A: Activation of vagal afferents after intravenous injection of interleukin-1beta: role of endogenous prostaglandins. J Neurosci 18, 9471-9479, 1998

Entschladen F, Lang K, Drell TL, Joseph J, Zaenker KS: Neurotransmitters are regulators for the migration of tumor cells and leukocytes. Cancer Immunol Immunother 51, 467-482, 2002 doi:10.1007/s00262-002-0300-8

Erin N, Boyer PJ, Bonneau RH, Clawson GA, Welch DR: Capsaicin-mediated denervation of sensory neurons promotes mammary tumor metastasis to lung and heart. Anticancer Res 24, 1003-1009, 2004

Erin N, Zhao W, Bylander J, Chase G, Clawson G: Capsaicin-induced inactivation of sensory neurons promotes a more aggressive gene expression phenotype in breast cancer cells. Breast Cancer Res Treat 99, 351-364, 2006 doi:10.1007 s10549-006-9219-7 PMid:16583263

Esteban F, Munoz M, Gonzalez-Moles MA, Rosso M: A role for substance P in cancer promotion and progression: a mechanism to counteract intracellular death signals following oncogene activation or DNA damage. Cancer Metastasis Rev 25, 137-145, 2006 doi:10.1007/s10555-006-8161-9 PMid:16680578

Gaykema RP, Chen CC, Goehler LE: Organization of immune-responsive medullary projections to the bed nucleus of the stria terminalis, central amygdala, and paraventricular nucleus of the hypothalamus: evidence for parallel viscerosensory pathways in the rat brain. Brain Res 1130, 130-145, 2007 doi:10.1016/j.brainres.2006.10.084 PMid:17169348

Gidron Y, Perry H, Glennie M: Does the vagus nerve inform the brain about preclinical tumours and modulate them? Lancet Oncol 6, 245-248, 2005 doi:10.1016/S1470-2045(05)70096-6 PMid:15811620

Goehler LE, Gaykema RP, Hansen MK, Anderson K, Maier SF, Watkins LR: Vagal immune-to-brain communication: a visceral chemosensory pathway. Auton Neurosci 85, 49-59, 2000 doi:10.1016/S1566-0702(00)00219-8 PMid:11189026

Hanahan D, Weinberg RA: The hallmarks of cancer. Cell 100, 57-70, 2000 doi:10.1016/S0092-8674(00)81683-9 PMid:10647931

Hebert MA, Serova LI, Sabban EL: Single and repeated immobilization stress differentially trigger induction and phosphorylation of several transcription factors and mitogen-activated protein kinases in the rat locus coeruleus. J Neurochem 95 , 484-498, 2005 doi:10.1111/j.1471-4159.2005.03386.x PMid:16190871 
Hodgson DM, Yirmiya R, Chiappelli F, Taylor AN: Intracerebral HIV glycoprotein ( gp120) enhances tumor metastasis via centrally released interleukin-1. Brain Res 781, 244-251, 1998 doi:10.1016/S0006-8993(97)01243-2 PMid:9507152

Hodgson DM, Yirmiya R, Chiappelli F, Taylor AN: Intracerebral interleukin-1beta impairs response to tumor invasion: involvement of adrenal catecholamines. Brain Res 816, 200-208, 1999 doi:10.1016/S0006-8993(98)01185-8 PMid:9878736

Hoffman GE, Smith MS, Verbalis JG: c-Fos and related immediate early gene products as markers of activity in neuroendocrine systems. Front Neuroendocrinol 14, 173-213, 1993 doi:10.1006/frne.1993.1006 PMid:8349003

Hollis JH, Lightman SL, Lowry CA: Integration of systemic and visceral sensory information by medullary catecholaminergic systems during peripheral inflammation. Ann N Y Acad Sci 1018, 71-75, 2004 doi:10.1196/annals.1296.008 PMid:15240354

Kergozien S, Delcros JG, Jouan H, Moulinoux JP: Induction of Fos protein expression in spinal cord neurons of tumour-bearing rats. Br J Cancer 80, 1512-1517, 1999 doi:10.1038/sj.bjc.6690554 PMid:10408391

Kiecolt-Glaser JK, Glaser R: Psychoneuroimmunology and cancer: fact or fiction? Eur J Cancer 35, 1603-1607, 1999 doi:10.1016 S0959-8049(99)00197-5 PMid:10673969

Konsman JP, Blomqvist A: Forebrain patterns of c-Fos and FosB induction during cancer-associated anorexia-cachexia in rat. Eur J Neurosci 21, 2752-2766, 2005 doi:10.1111/j.1460-9568.2005.04102.x PMid:15926923

Lang K, Entschladen F, Weidt C, Zaenker KS: Tumor immune escape mechanisms: impact of the neuroendocrine system. Cancer Immunol Immunother 55, 749-760, 2006 doi:10.1007/s00262-006-0126-X

Leo NA, Bonneau RH: Chemical sympathectomy alters cytotoxic T lymphocyte responses to herpes simplex virus infection. Ann N Y Acad Sci 917, 923-934, 2000

Mareel M, Leroy A: Clinical, cellular, and molecular aspects of cancer invasion. Physiol Rev 83, 337-376, 2003

Masek K, Slansky J, Petrovicky P, Hadden JW: Neuroendocrine immune interactions in health and disease. Int Immunopharmacol 3, 1235-1246, 2003 doi:10.1016/S1567-5769(03)00015-8 PMid:12860179

Mikkelsen JD, Vrang N, Mrosovsky N: Expression of Fos in the circadian system following nonphotic stimulation. Brain Res Bull 47, 367-376, 1998 doi:10.1016/S0361-9230(98)00121-X PMid:9886789

Mravec B, Gidron Y, Hulin I: Neurobiology of cancer: Interactions between nervous, endocrine and immune systems as a base for monitoring and modulating the tumorigenesis by the brain. Semin Cancer Biol 18, 150-163, 2008 doi:10.1016/j. semcancer.2007.12.002 PMid:18201897

Mravec B, Gidron Y, Kukanova B, Bizik J, Kiss A, Hulin I: Neural-endocrine-immune complex in the central modulation of tumorigenesis: facts, assumptions, and hypotheses. J Neuroimmunol 180, 104-116, 2006 doi:10.1016/j.jneuroim.2006.07.003 PMid:16945428

Mravec B, Hulin I: Does vagus nerve constitute a self-organization complexity or a "hidden network"? Bratisl Lek Listy 107 , 3-8, 2006

Nance DM, Sanders VM: Autonomic innervation and regulation of the immune system (1987-2007). Brain Behav Immun 21, 736-745, 2007 doi:10.1016/j.bbi.2007.03.008

Paintal AS: Vagal sensory receptors and their reflex effects. Physiol Rev 53, 159-227, 1973

Pirnik Z, Mikkelsen JD, Kiss A: Fos induction in the rat deep cerebellar and vestibular nuclei following central administration of colchicine: a qualitative and quantitative time-course study. Brain Res Bull 61, 63-72, 2003 doi:10.1016 S0361-9230(03)00064-9 PMid:12788208

Quan N, Banks WA: Brain-immune communication pathways. Brain Behav Immun 21, 727-735, 2007 doi:10.1016/j. bbi.2007.05.005

Reiche EM, Morimoto HK, Nunes SM: Stress and depression-induced immune dysfunction: implications for the development and progression of cancer. Int Rev Psychiatry 17, 515-527, 2005 doi:10.1080/02646830500382102 PMid:16401550

Sephton S, Spiegel D: Circadian disruption in cancer: a neuroendocrine-immune pathway from stress to disease? Brain Behav Immun 17, 321-328, 2003 doi:10.1016/S0889-1591(03)00078-3

Spiegel D: Embodying the mind in psychooncology research. Adv Mind Body Med 15, 267-273; discussion 275-281, 1999

Tashiro M, Juengling FD, Reinhardt MJ, Brink I, Hoegerle S, Mix M, Kubota K, Yamaguchi K, Itoh M, Sasaki H, Moser E, Nitzsche EU: Reproducibility of PET brain mapping of cancer patients. Psychooncology 9, 157-163, 2000 doi:10.1002 (SICI)1099-1611(200003/04)9:2<157::AID-PON452>3.0.CO;2-Y PMid:10767753

Wrona D: Neural-immune interactions: an integrative view of the bidirectional relationship between the brain and immune systems. J Neuroimmunol 172, 38-58, 2006 doi:10.1016/j.jneuroim.2005.10.017 PMid:16375977

Yang H, Wang L, Ju G: Evidence for hypothalamic paraventricular nucleus as an integrative center of neuroimmunomodulation. Neuroimmunomodulation 4, 120-127, 1997

Yang ZJ, Rao ZR, Ju G: Evidence for the medullary visceral zone as a neural station of neuroimmunomodulation. Neurosci Res 38, 237-247, 2000 doi:10.1016/S0168-0102(00)00165-6 PMid:11070190 